http://dx.doi.org/10.5007/2175-7968.2014v1n33p287

\title{
O EFEITO PIGMALEÃO: BERNARD SHAW E AS RELEITURAS DE OS SIMPSONS
}

\author{
Sílvia Maria Guerra Anastácio* \\ Universidade Federal da Bahia
}

\author{
Célia Nunes Silva** \\ Universidade Federal da Bahia
}

\begin{abstract}
Resumo:Este artigo surgiu do interesse de estudar o efeito Pigmaleão e o modo como esse tema tem se modificado ao longo do tempo. Busca-se investigar como o mito do Pigmaleão teria dado origem a uma variedade de hipertextos que ressignificam esse objeto de análise, especialmente na mídia contemporânea, em que os episódios das séries da animação Os Simpsons dialogam com uma obra prima de Bernard Shaw. Assim, surgem os seguintes questionamentos: Como os episódios de Pygmoelian e My Fair Laddy reinterpretam o signo do velho mito Pigmaleão? Que efeitos são utilizados para ressignificar esse mito para os telespectadores contemporâneos? E quais as questões ideológicas que motivariam essas releituras do mito grego?
\end{abstract}

Palavras-chave: Pigmaleão. Bernard Shaw. Os Simpsons. Releitura.

\footnotetext{
* Professora Titular do Instituto de Letras da Universidade Federal da Bahia. Doutorado em Comunicação e Semiótica pela PUC-SP (1998) e Pós-Doutorado em Literatura Comparada pela UFMG (2003). Universidade Federal da Bahia UFBA. Salvador, Bahia, Brasil. E-email: smganastacio10@gmail.com

** Professora do Departamento de Neurociência e Saúde Mental da FAMEB/ UFBA e Supervisora da Residência Médica de Psiquiatria do Complexo HUPES/ UFBA. Doutorado em Medicina pela Universidade Federal da Bahia (1997). Universidade Federal da Bahia - UFBA. Salvador, Bahia, Brasil E-email: celianunessilva@yahoo.com.br
} 


\title{
THE PYGMALION EFFECT: BERNARD SHAW AND THE SIMPSONS' REINTERPRETATIONS
}

\begin{abstract}
This article has arisen from the interest to study the Pygmalion effect and how this theme has changed through time. The aim is to investigate how the myth of Pygmalion would have given rise to a variety of hypertexts that reframe such object of analysis, especially in contemporary media, in which episodes of the animated series The Simpsons dialogue with a masterpiece by Bernard Shaw. Thus, the following questions arise: How do the episodes Pygmoelian and My Fair Laddy reinterprete the sign of the old Pygmalion myth? Which effects are used to reframe this myth for contemporary viewers? And which ideological issues would motivate such reinterpretations of the Greek myth?
\end{abstract}

Keywords: Pygmalion. Bernard Shaw. The Simpsons. Reframe.

Considerando que no domínio da Semiótica, o 'efeito' pode ser considerado um fator importante dentro do processo comunicativo, é instigante estudar o efeito Pigmaleão e o modo como esse motivo tem se modificado através dos séculos. Culturas e locais de fala diversos têm retrabalhado esse efeito, levando-se em conta que cada vez que ele é revisitado volta a ser reconfigurado de modo diverso, lançando novos olhares sobre um antigo mito grego. Poder-se-ia perguntar como um hipotexto como o mito do Pigmaleão teria dado origem a uma variedade de hipertextos que ressignificam o velho motivo, especialmente na mídia contemporânea em que os episódios das séries da animação Os Simpsons interagem com a obra prima de Bernard Shaw, de modo surpreendente.

A tradução intersemiótica, que remoldura textos, propondo-lhes múltiplas interpretações não é uma prática nova. A era midiática, contudo, tem intensificado esse fenômeno, contando com o poder tecnológico que desafia a velha noção de autoria em que cada interpretação aparece como um novo original com uma aura própria. Foi o autor Bernard Shaw quem primeiro revisitou a própria obra ao adicionar à versão da peça publicada em 1916, um prefácio explicativo dizendo por que a protagonista Eliza Dolittle não poderia ter se casado com o Professor Higgins. Ao fazê-lo, abriu novas 
possibilidades para o signo Pigmaleão continuar a ser desconstruído e rearrumado, o que será alvo do presente artigo.

Afinal, quem foi Bernard Shaw e por que é considerado um escritor tão importante da língua inglesa? Uma citação famosa do dramaturgo Bernard Shaw (1856-1950) consegue dar uma ideia da sua personalidade: "As coisas não me acontecem; sou eu que aconteço às coisas" (SHAW, 1949, s/p.). Trata-se de uma fala típica de Shaw, cujo discurso sempre revelava um humor sutil e uma inteligência aguçada, em um tom sempre comprometido com as críticas sociais. Durante mais de cinquenta anos, criticou os esnobes, ridicularizando seus valores e vários temas considerados como sagrados na sua época, como o casamento, as relações entre pais e filhos e as diferenças sociais. Shaw usou o dom da sátira, que dominava tão bem, para mostrar aos seus contemporâneos as incongruências da vida social da época. Viveu na transição entre a Era Vitoriana (1837-1900) e a modernidade do século XX, tendo comentado com um amigo que:

\begin{abstract}
Tendo, naturalmente, uma atitude séria perante a vida, logo aprendi a ver o mundo como ele, de fato, era não me deixando enganar de maneira nenhuma pela paz e prosperidade da Época Vitoriana. Era a paz de lunáticos que viviam num mundo da fantasia; aquela prosperidade não tinha nenhuma consistência e tenho prazer em escarnecer a Época Vitoriana. (SHAW, 1949, s/p.)
\end{abstract}

É evidente que Shaw desprezava os ricos comerciantes da época, que pareciam satisfeitos com a posição confortável em que viviam e o seu "lunático [...] mundo da fantasia". Eles olhavam os pobres com desdém, considerando-os fruto da imoralidade ou da indolência. Os vitorianos, que se gabavam de seu código moral inflexível, glorificavam o Império Britânico e, para eles, o ícone de respeitabilidade era a rainha Vitória (1837-1901), que deu nome à época. Ela defendia a leitura da Bíblia e a pregação de sermões 
religiosos. Contudo, os sete pecados da Revolução Industrial estavam, então, sempre presentes: "a imundice, as fábricas perigosas; as longas horas de trabalho desumano; a exploração do trabalho infantil e das mulheres; os baixos salários, as favelas e o desemprego" (POOLEY, 1949, p. 413). As mulheres eram seres frágeis, inferiores e inúteis; só lhes sendo permitido ensinar, fazer algum tipo de trabalho social, ou trabalhar em loja, enfim, serviços em que a sensibilidade feminina estaria a salvo.

Shaw estava lá para testemunhar tudo isso, inclusive, no século XX, a queda do império britânico do auge do poder que tinha atingido na Época Vitoriana. A classe trabalhadora começou a ter acesso a novas oportunidades no mundo dos negócios e as colônias britânicas, símbolos do antigo poder inglês, se foram dispersando. Ao mesmo tempo, eclodiram movimentos nacionalistas na Índia e em outras regiões do Império, incluindo a Irlanda. Havia o desejo de uma maior autonomia doméstica, o que naturalmente influenciou a política e a literatura da época.

Shaw era irlandês. Nasceu em Dublin, de uma família inglesa de classe média que se mudou para Londres em 1876. De 1880 até 1911, foi um importante líder social, que clamava por reformas. Acreditava que o homem era capaz de resolver seus problemas controlando as forças produtivas visando o interesse do bem comum.

Sua primeira peça surgiu em 1893 e começou, então, a escrever com direções minuciosas, para ver as próprias peças no palco. $\mathrm{O}$ fato é que a sua argumentação poderosa e a comicidade das peças que escrevia acabaram chamando a atenção do público (POOLEY, 1963).

Shaw demonstrou tamanha sagacidade para escrever sobre as classes sociais que acabou recebendo vários prêmios, inclusive o Prêmio Nobel de Literatura em 1925. Tinha duas grandes preocupações na vida: o teatro e o desejo de reformar o alfabeto. Na peça Pigmaleão, originalmente Pygmalion, que aborda a ilusão de minimizar a grande distinção existente entre as classes sociais, o protagonista masculino é um professor de fonética que pretende transformar uma pobre florista que fala uma variante do inglês conhecido como 'cock- 
ney' (dialeto de um subúrbio ao extremo Leste de Londres) em uma dama. Ele consegue seu intento utilizando para isso o alfabeto fonético, pois Shaw acreditava que a fonética seria a única solução possível para os ingleses se comunicarem adequadamente. Ao morrer, o testamento do autor estipulava que uma grande soma de dinheiro que deixara fosse utilizada para promover tal reforma.

A fonte de inspiração da peça foi um mito clássico, que haveria de tornar-se o favorito de todos os tempos, de onde veio a história de Pigmaleão, um nome grego que remonta a origens fenícias. O mito conta a história de um escultor que vivia em Cipro, uma ilha no Mediterrâneo, perto da Turquia, originalmente uma colônia britânica. Como costumasse por defeitos em todas as mulheres, decidiu ficar solteiro, pois nenhuma esposa lhe servia. Mas ao esculpir a estátua de uma linda mulher em marfim, chamada Galatea, achou a sua criação tão perfeita que acabou se apaixonando por ela. A deusa do amor, Vênus, decidiu então ouvir as preces do apaixonado escultor, dando alma à estátua, portanto, vida. Pigmaleão acabou casando-se com Galatea (CIVITA, 1973, p. 150).

Na base da cognição humana estão os mitos primitivos das primeiras narrativas que ajudariam o homem a dar sentido ao mundo ou conhecê-lo melhor. É possível argumentar que: "A natureza essencial do mito [...] tem a sua origem não no nível racional, mas da imaginação criativa cujo poder se faz sentir sobre os nossos mais profundos arquétipos e esquemas de pensamento." (DANESI, 1994, p. 101-102)

Shaw decidiu usar esse mito de Pigmaleão para escrever uma peça sobre um professor ranzinza, Higgins, que costumava abusar dos outros por causa dos seus modos grosseiros e rudes. No prefácio que acrescenta à versão de 1916, o autor enfatiza a importância da Fonética:

$\mathrm{O}$ inglês não tem nenhum respeito pela própria língua e não ensina os filhos a falar. Soletra tão mal que ninguém é capaz de dominar esses sons. É impossível um inglês abrir 
a boca sem que seja amado ou odiado por um outro inglês... O alemão e o espanhol podem ser aprendidos pelos estrangeiros. O inglês não é acessível nem aos próprios ingleses. O que a Inglaterra precisa hoje é de um foneticista entusiasmado e cheio de energia. É por isso que o escolhi como o herói de uma peça popular... Se a peça fizer com que o povo se conscientize da importância dos foneticistas para que sejam considerados hoje como os mais importantes da Inglaterra, a peça já terá cumprido a sua meta. (SHAW, $1916, \mathrm{~s} / \mathrm{p}$.$) .$

Portanto, o tema é o processo de transformação de alguém que consegue esse intento ao aprender a falar a própria língua, o inglês, utilizando-se para tanto a Fonética. O professor Higgins aposta com seu amigo o Coronel Pickering, outro foneticista, que conseguiria essa proeza. No processo, Higgins e a aluna, Eliza Doolittle, ficam muito próximos um do outro, mas como o professor tratava-a sempre muito mal, bombardeando-a com maus tratos, ela acaba fugindo de casa, no final. Apesar de cortejada por um jovem Freddy Eynford-Hill, que não tem recursos, mas está apaixonado por ela, a Eliza Doolittle ama o professor. Mas a peça não a mostra casada com o professor e a história termina meio que em aberto onde tudo pode acontecer.

É interessante que, a partir dessa história, tantas outras surgiram sob a influência do mesmo hipotexto (GENETTE, 2003), o mito grego, que serviu como fonte inspiradora de tantos hipertextos homônimos. Poder-se-ia apontar os seguintes:

Pigmalion (ópera) uma ópera de 1748 por Jean-Philippe Rameau

Il Pigmalione, uma ópera de 1816 por Donizetti

Pygmalion (ópera) um drama do final do século XVIII por Georg Anton Benda

Pygmalion (peça) uma peça de 1913 por George Bernard Shaw 
Pygmalion (filme) um filme de 1938 baseado na peça de George Bernard Shaw, por Anthony Asquith e Leslie Howard

Pygmalion (álbum), um musical de 1994 pela Banda Slowdive

Pygmoelian (animação) episódio de Os Simpsons de 2000

Além dessas obras, muitas peças têm ido ao palco ou outras histórias vão para as telas sob a influência do mesmo efeito Pigmaleão. Devido a atrasos na montagem da primeira produção inglesa, que deveria ocorrer em Londres, a primeira apresentação ocorreu em Viena, 1913, uma tradução alemã da peça de Shaw. Por isso, a produção inglesa só ocorreu em 1914, dirigida pelo próprio Bernard Shaw. Tantas outras adaptações se seguiram e, em 1956, os músicos da Broadway, Alan Jay Lerner e Frederick Loewe acrescentaram melodias para os personagens da história. O musical foi um sucesso de bilheteria em Nova York, em Londres, e ao ir para as telas em 1964, a versão cinematográfica My Fair Lady, com Audrey Hepburn no papel de Eliza, ganhou oito oscars. Quanto à recepção dessa peça no Brasil, em 1962, a atriz Bibi Ferreira desempenhou o papel da principal personagem, Eliza. Novamente, em 2007, é a vez de Amanda Acosta trazer à cena o efeito Pigmaleão.

O final da peça de Shaw tem sofrido modificações ao longo dos anos. Na versão de 1913, Eliza, ao pensar que o professor Higgins não sente nada por ela e ver que fora alvo de uma simples aposta, fica em dúvida se vale à pena casar-se com o jovem Freddy Eynsford Hill. De fato, Shaw aborrecia-se com o fato das plateias desejarem sempre um final romântico feliz, chegando, em 1916, a escrever um prefácio em que explicava porque seria impossível para Higgins casar-se com Eliza. Nesta versão, é Eliza quem abusa de Higgins e lê-se:

Pygmalion - Sequel ou sequência de 1916. O que aconteceu depois é que parece incrível como Eliza ainda consegue 
tomar conta da casa de Wimpole Street \{a do professor Higgins\}, apesar da loja que tem de cuidar e da própria família [...]. Ela nunca mais parou de reclamar com Higgins e isso começou naquela noite fatal quando ganhou a aposta para ele. Ela sempre lhe responde mal a mais leve provocação, ou mesmo sem razão nenhuma. Não ousa aborrecê-la mais, dizendo que Freddy é inferior a ele ou que lhe fica a dever na inteligência. Quando ele se irrita e abusa das outras pessoas ou as ridiculariza, ela o enfrenta tão cruelmente que o coronel tem que lhe pedir, às vezes, para ser mais boazinha com Higgins. [...] Acostumou-se a tê-la por perto e é tão dependente dela para todo o tipo de pequenos serviços, que sentiria falta se fosse embora [...]. Ela ainda alimenta momentos secretos em que sonha estar com ele a sós, numa ilha deserta, longe de qualquer obrigação e com ninguém mais por perto pra se preocupar, em que possa tirá-lo do pedestal e vê-lo fazendo amor como qualquer homem comum. Todos nós temos nossas fantasias. Mas no dia-a-dia, longe dos sonhos e das fantasias, ela continua gostando de Freddy e do coronel; ela não gosta de Higgins' e do Sr. Doolittle. (SHAW, 1916, s.p.).

As adaptações subsequentes têm modificado o final da história de um modo ou de outro. Apesar da insistência de Shaw de que o final não deveria mudar, ele terminou dando um final mais aberto para a versão fílmica de 1938: ao invés de pensar em se casar com Freddy, Eliza se reconcilia com Higgins na cena final e volta para ele, para satisfação do professor. Fica aberta a possibilidade de um futuro casamento entre eles. Também a versão musical de My Fair Lady no palco e no filme de 1964 têm finais felizes e sempre abertos. É interessante ver como o motivo da metamorfose continua a fascinar as pessoas e, ao longo do tempo, tem adquirido novas roupagens. O efeito Pigmaleão reaparece, ainda, em um filme inglês chamado Educating Rita, "Educando Rita", de 1983, pelo diretor Lewis Gilbert, que conta um caso de amor entre uma cabeleireira e um professor universitário alcoólatra; Rita entra na universidade 
para estudar literatura inglesa e sua vida muda, bem como também a vida dele.

Portanto, múltiplos arranjos continuam a surgir, a partir de uma velha receita ou de um signo repetidamente desconstruído, que sempre assume novas feições, de acordo com o lugar de fala de cada público alvo. A ciência que estuda o signo, explica-o como "qualquer marca, movimento corporal, símbolo \{qualquer sinal, enfim $\}$ [...] usado para indicar ou transmitir pensamentos, informações, comandos" (DANESI, 1994, p. 11).

Como será que os episódios de Os Simpsons, Pygmoelian e My Fair Laddy apresentam o signo do velho mito Pigmaleão, sugerindo novos efeitos para os telespectadores contemporâneos? Observando os títulos da animação, há um diálogo entre eles e a peça Pigmaleão (1912), ou com a adaptação musical para o cinema (1964). Genette chamaria esse diálogo de 'arquitextualidade'(GENETTE, 2005 , p. 17), um eco entre títulos diferentes que provoca uma teia de associações no receptor.

O título da animação Pygmoelian, uma corruptela do Pygmalion ou Pigmaleão de Shaw alude ao protagonista do décimo sexto episódio de Os Simpsons, décima primeira temporada, que foi ao ar pela primeira vez no dia 27 de fevereiro de 2000. Moe Szylak é um personagem ficcional, um imigrante que se envergonha da sua etnia, talvez albanês ou eslavo, a julgar pelo seu sobrenome. Moe é dono de um bar onde serve Cerveja Duff, metendo-se sempre em atividades ilícitas, como servir bebida alcoólica sem a devida licença. Muito feio, diz-se no episódio que tem orelhas de couve-flor e focinho de peixe.

Nesse episódio, Os Simpsons vão ao festival da cerveja Duff e Moe Szyslak entra em uma competição para ver quem era o melhor vendedor de cerveja. Como se pode perceber, o motivo da aposta ou da competição em Shaw reaparece também aqui. Como Moe vence a competição, seu rosto deveria aparecer no calendário anual da cerveja Duff, mas como é muito feio, isso não acontece. Sentindo-se humilhado, Moe decide fazer plástica e consegue ter um belo rosto. Aceita, então, o papel de protagonista de uma novela, 
mas curioso em desvendar como acaba a história, fica sabendo que o seu personagem morre no final. Furioso, ele e Homer decidem revelar o que pensam ser o final da novela aos telespectadores, sem saber que, de fato, os personagens apenas morrem em um sonho, e não de fato. A equipe do programa fica tão brava com esse comportamento, que resolve despedir Moe. Ao deixar o estúdio, recebe um ferimento no rosto e retorna a sua antiga aparência.

Quanto ao título do outro episódio, My Fair Laddy, ele interage com o musical levado My Fair Lady. Há um trocadilho que o telespectador compreende ao perceber que a história não é sobre uma jovem dama, como no caso da peça de Shaw, mas sobre um rapaz $(l a d)$, como sugere o título. No décimo sétimo episódio, de 2 de fevereiro de 2006, Bart, para se vingar de um professor de ginástica agressivo, acidentalmente destrói a casa onde morava o zelador da escola elementar de Springfield, Willie. Marge acolhe-o e Lisa decide ajudá-lo a ter uma vida melhor, transformando-o em um perfeito cavalheiro. É o projeto que Lisa resolve apresentar na feira de ciências da escola. Assim, ela o ajuda a falar com um sotaque escocês mais suave, a se comportar e se vestir com elegância, além de ensiná-lo regras de etiqueta. O seu projeto social acaba ganhando o primeiro premio na feira e, logo depois, Willie começa a trabalhar em um restaurante de classe. Só então se dá conta que ele era mais feliz antes e acaba voltando ao velho emprego e à velha casa.

Como se pode observar, há uma mudança de gênero no enfoque dado nos episódios de Os Simpsons. Em Pygmoelian, é um homem, Moe, que muda radicalmente, e em My Fair Laddy, Lisa esforça-se para educar um rapaz escocês: "Aposto que posso transformá-lo num verdadeiro cavalheiro e a tempo de participar da feira de ciências da escola" (07:12). Logo, a condição feminina aparece revisitada no mundo contemporâneo, aparecendo os homens mais fracos que as mulheres. Enquanto a personagem de Shaw, um escritor feminista, cresce e se torna uma pessoa autônoma, os personagens masculinos de Os Simpsons não conseguem dar um salto, retomando, no final, a sua condição inicial. 
Poder-se-ia perguntar que tipo de questões ideológicas estaria por trás de semelhantes releituras do mito grego? O mito aborda o motivo do voyeurismo masculino, reaproveitado por Shaw em seu texto, mas às avessas. O objeto do olhar do escultor Pigmaleão é uma estátua de marfim em forma de mulher; sem identidade, sem alma, sem voz, que, por um passe de mágica, ganha vida. Considerando que Shaw presenciou, na época vitoriana, o modo como as mulheres eram tratadas naquele mundo patriarcal em que não tinham acesso ao discurso, essa condição teria que ser traduzida na peça. Tal atitude se reflete no modo rude e ranzinza como o professor de fonética Higgins tratava Eliza, não perdendo a oportunidade de humilhar a aluna sempre que podia. Assim, Shaw critica a condição das mulheres da época, além de denunciar o abismo existente entre as classes sociais, não podendo os mais humildes falar sem que um "outro inglês \{de nível social mais elevado\} o odiasse ou o desprezasse por isso" (SHAW, 1916, p. 1).

O modo abusivo do chauvinista Higgins que, com os seus maus tratos, ameaçava Eliza até de passar fome se ela não pronunciasse as vogais corretamente, é traduzido metaforicamente para a animação na cena em que o professor de ginástica ataca os alunos no início de My Fair Laddy. No episódio de Os Simpsons, a palavra bullying, que significa abusar, maltratar, é repetida três vezes e bombardment, bombardear (mento) aparece quinze vezes. Logo, o mesmo motivo, frequente no texto de Shaw para descrever Higgins, é assim adaptado para a animação, na época contemporânea, em que os abusos às crianças, inclusive sexuais, se tornaram uma grande preocupação.

Na contemporaneidade, Os Simpsons ainda mostram que ambos, homens e mulheres, fazem cirurgia plástica ou buscam, de um modo ou de outro, melhorar a aparência, mas acabam enfrentando problemas de identidade. Essas questões relacionadas à metamorfose e identidade aparecem em My Fair Laddy em que, logo no início, o professor de ginástica da escola elementar avisa que vai se ausentar para submeter-se a uma cirurgia e mudar de sexo. Até Homer enfrenta problemas de identidade porque o seu velho par 
de calças azuis deixou de ser fabricado. Queixa-se ele: "Marge, rasguei minhas calças-as únicas que entendem o meu complexo de chorão" (01: 33). Portanto, a questão da identidade é recorrente no efeito Pigmaleão.

Essa questão também aparece no episódio de Os Simpsons, Pigmaleão, quando o protagonista decide fazer uma plástica por ser muito feio, mas acaba tendo que enfrentar problemas de identidade. Afinal, "a cirurgia plástica lhe dá uma boa aparência externa, mas por dentro você continua se sentindo mal como sempre" (07:35). Ao final, quando o personagem sofre um acidente e vê o seu rosto todo deformado, diz: "Aquele rosto bonito era legal, mas dava muito trabalho para manter" (19:59). Assim, da mesma forma que a peça de Shaw se refere, com um humor sutil, a questões de identidade que estão sempre surgindo, o enredo do episódio de Os Simpsons também alude a tais problemas.

Outro efeito da peça de Shaw adaptado à cultura americana e reajustado para o dia de hoje é o motivo da competição e da aposta, que aparece em ambos os episódios de Os Simpsons. Em Pygmoelian, a competição dos garçons no festival de cerveja é uma oportunidade para se abordar o motivo do alcoolismo, preocupação constante na cultura americana. Em Os Simpsons, insiste-se que é importante beber "com responsabilidade", além de se ter um "motorista escalado" para conduzir o veículo de volta para casa, após o festival. Esse motorista tem, portanto, uma grande responsabilidade e, por isso, não deve beber. Até as crianças precisam se conscientizar do perigo da bebida. No episódio da animação, elas são convidadas a rodar em um brinquedo do parque semelhante a uma roda-gigante para terem a sensação "de como é ficar bêbado" (01: 25). Ficam então, tontos e se sentem mal. Além disso, há outras alusões a problemas de bebida nos EUA, como o fato da licença de Moe "de vender álcool" ter expirado (06: 33). O desenho também mostra grandes bebedores na história americana, como o general Ulysses Grant, o estadista Benjamin Franklin (01: 57). E outro motivo que reaparece no episódio é a Grécia, local de origem 
do mito Pigmaleão e que ajuda a dar nome ao bar de Moe, "O Bar da Batata Grega". Também o alcoolismo é aludido em My Fair Laddy quando o professor de ginástica se refere à “Associação dos Alcoólicos Anônimos" (03:43), uma entidade conhecida em todo o mundo.

O que o leitor ou espectador percebe é que não só Shaw, como também a direção dos episódios de Os Simpsons, sabem usar o humor para tratar de assuntos sérios, instrutivos e passar ideias importantes. Shaw ridiculariza os ideais de casamento, a moralidade e a vida de aparências da classe média, enquanto a equipe da criação de Os Simpsons usa o humor para satirizar a sociedade contemporânea, aproveitando para abordar problemas da atualidade.

Muito desse humor de Shaw deve-se ao uso de aforismas que também fazem a audiência refletir sobre a vida. São insights expressos de forma concisa e econômica, semelhantes aos provérbios que sempre têm uma lição de moral. A diferença entre os aforismas e provérbios é que os provérbios fazem parte do folclore de uma cultura, são anônimos e os aforimas, geralmente, se sabe quem os escreveu. Na peça de Shaw, Eliza diz que "a diferença entre uma dama e uma florista não é como ela se comporta, mas como é tratada" (Pygmalion, 1916, p. 59). Esse é um bom exemplo de aforisma em Shaw, enquanto que em Os Simpsons, tal traço estilístico também é recorrente. No episódio My Fair Laddy, alguns exemplos de aforismas poderiam ser:

Willie - Meu pai me disse: "Você nunca vai ser nada. Você nasceu no lixo e dele não sairá" (09:24).

O pai de Willie - Deixe que ele mesmo corte o cordão umbilical Afinal, precisa aprender logo que a vida não é moleza, não (09:24).

Enquanto isso, em Pygmoelian, ouve-se que: 
O amigo de Moe - A cirurgia plástica pode lhe dar uma boa aparência, mas no fundo, você se sente mal com você mesmo (07:35).

O médico - Dediquei toda a minha vida a cuidar de doenças, a única que não dei jeito foi a que tenho na alma (16:21).

Portanto, os aforismas estão presentes no texto de Shaw e no dos Simpsons, ensinando lições sobre a vida, ou sobre questões de identidade, ou criticando a visão de mundo, especialmente da classe média, que Shaw insiste em repudiar em sua obra e que também o programa Os Simpsons denuncia; ou comentando a falta de sentimento das pessoas que não se sensibilizam com o sofrimento alheio, como no caso do Prof. Higgins, que parece não notar o sofrimento de Eliza.

Essa frieza, essa falta de sentimentos do Professor Higgins aparece em Os Simpsons de um modo muito econômico, em uma tomada de Pygmoelian, quando Moe se comove ao ver o próprio rosto, após a operação (11:24). Como um correlato objetivo (recurso literário em que a imagem mostra, de um modo pictórico, o que o personagem está pensando ou sentindo), o médico vê a lágrima de Moe como um simples vazamento no rosto e o cauteriza. Outro correlato objetivo, desta vez em My Fair Laddy, capaz de mostrar os sentimentos do personagem de um modo econômico é quando Willie olha-se no espelho e não se reconhece, mas vê alguém imitando um cavalheiro. Apenas "um espelho falante" (10:26).

Sugere-se, assim, uma crítica à cópia, a um modelo pré-definido. No texto de Shaw, este comportamento seria percebido na atitude de Eliza que, desejosa de passar de florista a uma dama, imitava o modo das pessoas falarem e se comportarem, a princípio de forma meramente mecânica. Esta e outras alusões ao musical e também ao mito grego que lhe dera origem apontam para questões de identidade e metamorfose.

De fato, o modo como o efeito Pigmaleão reaparece em ambos os episódios de Os Simpsons evoca índices do mito que lhes deu 
origem, sem nenhum compromisso de reproduzir o modelo. Esses hipertextos guardam traços das obras que lhes teriam servido de inspiração, Pygmoelion gerado por Pygmalion e My Fair Laddy por My Fair Lady, todos por sua vez, gerados, em última análise, pelo mito grego.

No nível icônico, ou seja, aquele que provoca na audiência impressões que a fazem associar a animação a outros textos pela similaridade que guardam um com o outro, é importante enfatizar o ritmo do episódio My Fair Laddy. É nesse episódio que o efeito icônico predomina, devido sobremaneira às repetições, especialmente à aliteração, ou às músicas que são semelhantes as do musical My Fair Lady. De acordo com a semioticista Lucia Santaella (1996), a música é a linguagem mais icônica que existe, considerando os níveis de percepção existentes, pois transporta o receptor da mensagem para todo tipo de tempos e locais, provocando nele as mais variadas impressões.

Em My Fair Laddy, várias aliterações engraçadas fazem o telespectador lembrar do musical e, enquanto em My Fair Lady, uma das frases mais conhecidas é : The rain in Spain fall mainly in the plain, no episódio da animação, ouve-se: What flows from the nose does not got on my clothes. Quanto às melodias, as seguintes linhas podem ser ilustrativas: All I want is a room somewhere do musical, na animação passa a: All I want is a place somewhere (05:15); também She's got it passa a I think he's got it, na voz de Liza de Os Simpsons (10:26); I could have danced all night muda para I could be indoors all night (15:52) na televisão e, há uma valsa em My Fair Laddy que lembra a cena do baile da embaixada no musical. Portanto, a musicalidade no nível icônico predomina em My Fair Laddy, o que imediatamente remete a audiência ao musical. De acordo com Deleuze, cópias ou ícones são como pretendentes bem fundados a uma união em que tal pretendente tem a primazia pela semelhança com o modelo pretendido (DELEUZE, 2006).

Já o outro episódio, Pygmoelian, é mais indicial, havendo menos semelhança com o modelo Pygmalion, embora guarde rastros 
dele. Voltando a Deleuze, os simulacros são como falsos pretendentes, construídos a partir de uma dissimilitude, que é o caso especialmente dessa animação. Segundo Deleuze:

O simulacro rompe suas cadeias e sobe à superfície, afirmando sua potência. [...] A reversão do platonismo significa fazer subir os simulacros, afirmar seus direitos entre os ícones ou as cópias.

[...] O simulacro não é uma cópia degradada, mas encerra uma potência positiva que nega tanto o original quanto a cópia [...]. Ele torna impossível a fixidez [...] e a determinação da hierarquia. (DELEUZE, 2006, p. 8).

A paródia de Os Simpsons, portanto, celebra a vitória do simulacro, da dissimilitude, que instaura outro original a partir do efeito que lhe dera origem e propõe uma nova proposta para o efeito Pigmaleão. Assim, no nível simbólico da percepção, aquele em que são ressaltadas as leis e convenções do processo de criação da animação é o gênero paródico que domina. Uma crítica social que mexe com o espectador com um aguçado senso de humor está presente no modo como o mito grego é atualizado e enriquecido pelos aspectos culturais do pólo de recepção. Nesse processo de criação de Os Simpsons, em que a lei maior é que as aparências enganam, a cultura de massa dá acesso a textos literários. Ao refletir sobre a democratização da arte, Walter Benjamin considera que:

Uma das tarefas mais importantes da arte foi sempre a de gerar [...] efeitos. (BENJAMIN, 1996, p. 192) [...] A massa é a matriz da qual emana toda uma atitude nova em relação à obra de arte [...] Para as massas, a obra de arte seria objeto de diversão, e para o conhecedor, objeto de devoção. 
[...] A massa distraída [...] absorve-a [...] e as leis de sua recepção coletiva [...] são extremamente instrutivas. A arte conseguirá realizar uma das mais difíceis e importantes \{tarefas\} sempre que mobilizar as massas [...]. A crescente proletarização e [...] massificação são dois lados do mesmo processo. (BENJAMIN, 1996, p. 4)

A crença de que a comunicação de massa pode dar acesso à literatura provou, mais uma vez, ser verdadeira, não apenas utilizando como veículo o famoso musical My Fair Lady, como também os episódios de Os Simpsons. É relevante enfatizar que cada releitura levanta novas questões e requer interpretações ou análises diversas, já que se acha contextualizada em um diferente sistema histórico e político. O fato de que cada nova releitura propõe desfechos ambíguos, com uma tendência a finais felizes, mostra que nenhum texto é sagrado e que, por isso, pode ser questionado, modificado, reinterpretado de uma maneira ou de outra. Shaw levanta questões que reaparecem em todas as gerações e culturas, que tocam diferentes comunidades e cada pessoa em particular. Mas até a mesma pessoa em momentos diferentes irá interpretar cada obra de arte à sua própria maneira, dependendo do contexto em que se situe. Assim, o respeito que cada indivíduo tem pela própria língua; ou questões sociais; ou morais; ou o fato de que as aparências enganam e de que a realidade é difícil de definir é parte do mundo de Shaw, perguntas que são formuladas e respondidas de formas diferentes, cada vez que a peça é revisitada. 


\section{Referências}

BENJAMIN, Walter. Obras Escolhidas. Magia e técnica, arte e política. São Paulo: Editora Brasiliense, 1996.

CIVITA, Roberto. Dicionário de Mitologia Greco-Romana. São Paulo: Abril Cultural, 1973.

DANESI, Marcel. Introduction: Thomas A. Sebeok and the Science of Signs. In: SEBEOK, Thomas. Signs. Toronto: University of Toronto Press, 1994.

DELEUZE, Gilles. Lógica do sentido. São Paulo: Perspectiva, 2006.

GENETTE, Gérard. Palimpsestos. A literatura de Segunda Mão. Edição Bilíngue. Tradução Luciene Guimarães e Maria Antônia Ramos Coutinho. Belo Horizonte: UFMG, 2005.

POOLEY, Robert. England in Literature. Illinois: Scott, Foresman and Company, 1963.

SANTAELlA, Lucia. Produção, linguagem e ideologia. São Paulo: Editora Cortez, 1996.

SHAW, Bernard. Pygmalion. New York: Brentano, 1916.

SHAW, Bernard. Sixteen Self-Sketches. Londres: Dodd, Mead \& Company, 1949.

Recebido em: 15/01/2014

Aceito em: 29/04/2014 